\title{
Revista Brasileira de Ciências do Esporte: encerrando um ciclo editorial
}

\author{
Felipe Quintão de Almeida' \\ Jaison José Bassani² \\ Ana Cristina Richter ${ }^{3}$ \\ Lisondra Invernizzi ${ }^{4}$ \\ Alexandre Fernandez Vaz ${ }^{5}$
}

\section{RESUMO}

Com base nos editoriais publicados na Revista Brasileira de Ciências do Esporte (RBCE), especialmente entre 2013 e 2018, o presente trabalho oferece uma análise dos últimos cinco anos de gestão do periódico, revisitando alguns traços da política científica adotada na RBCE. Desde essa perspectiva, busca refletir sobre dificuldades, desafios e dilemas da editoração científica no campo da educação física, especialmente no que se refere à profissionalização, à internacionalização, ao financiamento e à parceria com a Elsevier, editora de literatura médica e científica cujas plataformas oferecem tecnologia integrada e interatividade de conteúdo, facilitando o trabalho de divulgação do conhecimento científico e de editoração de periódicos. Tal facilidade não exime os editores, em meio às suas atividades científicas, de perder de vista a dimensão política de seu ofício e de exercer sua função como retaguarda crítica a esclarecer os processos de governamento

1 - Doutor, Universidade Federal do Espírito Santo, Centro de Educação Física e Desportos, Departamento de Ginástica, Vitória, ES, Brasil. fqalmeida@hotmail.com

2 - Doutor, Universidade Federal de Santa Catarina, Centro de Desportos, Departamento de Educacão Física, Florianópolis, SC, Brasil. jaisonbassani@uol.com.br

3 - Doutora, Pesquisadora Assistente do Núcleo de Estudos e Pesquisas Educação e Sociedade Contemporânea (NEPESC/UFSC). Contato: ana_tinaa@uol.com.br

4 - Doutora, Universidade Federal de Santa Catarina, Programa de Pós Graduação em Educação. Prefeitura Municipal de Florianópolis, Contato: lisandrainvernizzi@gmail.com

5 - Doutor, pesquisador CNPq 1C. Universidade Federal de Santa Catarina, Centro de Educação, Departamento de Estudos Especializados em Educação, Florianópolis, SC, Brasil. alexfvaz@uol.com.br

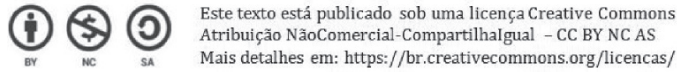


julho/2018

que envolvem a área da Educação Física, a produção e a divulgação do conhecimento e a intervenção que dele emerge.

Palavras-chave: Editoria. Periódico científico. RBCE. Atitude crítica

\title{
Brazilian Journal of Sport Sciences: the end of an editorial time
}

\begin{abstract}
Considering the editorials published in the Brazilian Journal of Sport Sciences (RBCE), especially between 2013 and 2018, this paper analyses the last five years of the journal's management, revisiting some of the scientific policy of RBCE. From this perspective, the main is to reflect on the difficulties, challenges and dilemmas of scientific publishing in Physical Education, especially regarding to professionalization, internationalization, financing and partnership with Elsevier. It is a publisher of medical and scientific literature whose platforms offer integrated technology and content interactivity, what makes easier the work of disseminating scientific knowledge and publishing of journals. This facility does not exempt the editors the political dimension of their office and their ask to make clear the processes of governance that involve Physical Education, production and dissemination of knowledge and the intervention that comes from it.
\end{abstract}

Keywords: Scientific publishing. Scientific journal. RBCE. Critical approach

\section{Revista Brasileña de Ciencias del Deporte: cerrando un ciclo editorial}

\section{RESUMEN}

Observando los editoriales de la Revista Brasileña de Ciencias del Deporte (RBCE), en especial los publicados entre 2013 y 2018, este artículo ofrece un análisis de los últimos cinco años de gestión de la revista, revisitando algunos rasgos de la política científica adoptada en la RBCE. Desde esta perspectiva, busca reflexionar sobre dificultades, desafíos y dilemas del trabajo editorial científico en la educación física, especialmente en lo que se refiere a la profesionalización, internacionalización, financiamiento y asociación con Elsevier, editora científica y médica cuyas plataformas ofrecen tecnología integrada e interactividad de contenido, facilitando el trabajo de divulgación del conocimiento científico y de publicación de revistas. Tal facilidad no exime a los editores, en medio de sus actividades científicas, de perder de vista la dimensión política de su oficio y de ejercer su función como retaguardia crítica a esclarecer los procesos de gobierno que involucran el área de la Educación Física, la producción y la divulgación del conocimiento y la intervención que de ahí se desarrolla.

Palabras clave: Publicación científica. Revista científica. RBCE. Abordaje crítico 


\section{INTRODUÇÃO}

No final de 2007, fomos convidados, pela direção nacional do Colégio Brasileiro de Ciências do Esporte, para editorar a Revista Brasileira de Ciências do Esporte (RBCE). Seu então presidente era Fernando Mascarenhas, que permaneceria por ainda dois anos à frente da entidade, e sua diretora científica era Yara Carvalho, logo substituída por Alexandro Andrade. Assumiríamos o lugar de Alex Branco Fraga e Silvana Goellner, editores do periódico no biênio 2005-2007. Nossa permanência no cargo atravessou outras do CBCE: as lideradas por Leonardo Alexandre Peyré-Tartaruga (2009-2013) e por Simone Rechia (2013-2017). Completamos uma década na condução da política científica da revista.

Uma vez aceito o desafio, a nova equipe, sob a supervisão dos editores Alexandre Fernandez Vaz e Marcus Aurélio Taborda de Oliveira, começou a se inteirar do processo de editoração, naquele momento "quase artesanal", do periódico científico. O grupo foi inicialmente composto também por Jaison José Bassani, Ana Cristina Richter e Felipe Quintão de Almeida, ${ }^{6}$ os três integrantes do Núcleo de Estudos e Pesquisas Educação e Sociedade Contemporânea, coordenado por Alexandre Fernandez Vaz na Universidade Federal de Santa Catarina (UFSC). A essa equipe, pouco tempo depois, juntaram-se Lisandra Invernizzi e Michele Carreirão Gonçalves do mesmo Núcleo. O convite aos novos membros esteve diretamente relacionado com o volume de trabalho, que aumentou exponencialmente, bem com a criação, em 2009, dos Cadernos de Formação da RBCE.

Embora o trabalho propriamente dito tenha começado com a preparação do v. 29, n. 2, o primeiro de 2008, os antigos editores ainda assinaram o editorial de despedida dessa edição. O editorial seguinte já tem como signatários os novos editores, ocasião para agradecer a seus antecessores, mas, também, para anunciar a primeira de muitas alterações na política científica: a suspensão dos números temáticos. Outras delas, e os desafios que as acompanharam, foram descritas em dois artigos (VAZ, ALMEIDA; BASSANI, 2014; ALMEIDA; BASSANI; VAZ, 2015) publicados ao final do primeiro quinquênio.

Nesta reflexão, preparada para a edição especial da Motrivivência, em comemoração aos trinta anos de seu vitorioso ciclo de vida, oferecemos uma análise dos últimos cinco anos de gestão, oportunidade para rever alguns traços da política científica adotada na RBCE, mas, ao mesmo tempo, refletir sobre outras dificuldades, desafios e dilemas da editoração científica no campo da Educação Física. Para tanto, retomamos, como documentos de análise, os vinte editoriais dos números regulares, publicados entre 2013 e $2018 .^{7}$

Em artigos anteriores (VAZ; ALMEIDA; BASSANI, 2014; ALMEIDA; BASSANI; VAZ, 2015), anunciamos que a RBCE entrara, em meados dos anos 2000, em novo momento do seu ciclo de vida, caracterizado, especialmente, pela busca da profissionalização e por maior visibilidade internacional. Nosso último quinquênio na gestão editorial visou, desse modo, a consolidar essas metas. Em relação ao primeiro tema, merece destaque a decisão de

6 Com a saída de Marcus Aurélio Taborda de Oliveira da condição de editor, Jaison José Bassani e Felipe Quintão de Almeida assumiram, a partir do v. 32, n. 2-4 de 2010, a função de editores adjuntos.

7 Do v. 35, n. 2 de 2013 até o v. 40, n. 1 de 2018. 
encerrar o contrato com a editora Tribo da Ilha, que havia substituído a Autores Associados no processo de editoração do periódico, e estabelecer parceria com a Elsevier, uma das maiores editoras de periódicos nas áreas de Ciência, Saúde e Tecnologia. Essa mudança foi anunciada no v. 36, n. 1 de 2014, que descreve as vantagens do contrato assinado:

\begin{abstract}
A ELSEVIER, a partir do volume 36.3, será a responsável pelo planejamento editorial, projeto gráfico, artes, ilustrações, diagramação, revisão gramatical dos textos em português, inglês e espanhol e revisão tipográfica de cada edição da RBCE. O objeto do contrato ainda prevê: implementação do sistema global ELSEVIER EES (ELSEVIER Editorial System ${ }^{\circledR}$ ) para submissão eletrônica de artigos da RBCE e processo de arbitragem por pares, inclusão da RBCE no Catálogo Internacional ELSEVIER (www.elsevier.com) e na Coleção Global ELSEVIER ScienceDirect ${ }^{\circledR}$, fechamento em formato específico (XML) para indexação no SciELO (Scientific Electronic Library Online) e no ScienceDirect ${ }^{\circledR}$, inserção nos artigos do número de DOI (Digital Object Identifier) atribuído pelo SciELO, adaptação do web site da RBCE, onde será disponibilizado, para acesso livre e gratuito, cada fascículo. Os artigos aprovados serão publicados em advance online. Este sistema é mais conhecido como ahead of print, ou seja, trabalhos aceitos por periódicos que ficam disponíveis online, mas sem ainda indicação de fascículos e páginas. Deste modo, o autores já terão suas pesquisas divulgadas e os leitores conhecerão mais cedo o conteúdo que será publicado no(s) próximo(s) número(s) do periódico. Isso oferecerá mais rapidez à publicação, minimizando, assim, um dos problemas mais sérios da editoração: a demora na divulgação dos artigos já aprovados.
\end{abstract}

A troca de editora, embora exitosa para a RBCE, resultou em exponencial aumento no volume de trabalho. Além de um treinamento orientado pela Elsevier para aprender a interagir com a nova plataforma, a equipe precisou migrar todo o conteúdo da revista para ela, realizar mudanças de layout e adequar tudo, dali por diante, às novas normas de publicação, pois o periódico passou a adotar, em substituição à ABNT, o estilo Vancouver. Trabalhávamos em perspectiva de internacionalização crescente da RBCE. Decidimos manter por mais tempo, para maximizar os esforços na transição em curso, a suspensão da submissão de artigos, anunciada no editorial do v. 35, n. 2 de 2013. Seguramente as mudanças impactaram o campo - que já estava "acostumado" com a "antiga" plataforma SEER -, especialmente porque a nova interface passou a exigir de colaboradores, na submissão de artigos e na avaliação dos manuscritos, algum grau de domínio da língua inglesa.

Embora o contrato assinado com a Elsevier tenha sido muito importante para avançar com o desejo da profissionalização (o que facilitou atender às múltiplas exigências bibliométricas e técnicas dos indexadores), antigos problemas ainda permaneciam. Continuamos a enfrentar, como descrevem os editoriais, dificuldades com o tempo de espera de avaliação e publicação, que ainda é muito grande (o que produz uma "fila para publicação"), ${ }^{8}$ situação só recentemente amenizada com o emprego do sistema ahead of print. A dificuldade com os revisores também se expressa na qualidade dos pareceres exarados, muitas vezes

8 Em levantamento realizado com as quatro edições de 2012, Devís-Devís, Villamón e Valcárcel (2014) concluem que houve uma demora de 18 meses e meio entre a recepção e a publicação dos artigos desse ano. 
mais adjetivos que analíticos. Há pareceres profícuos que perguntam pelas possibilidades e limites dos artigos submetidos, mas avaliações com apenas um parágrafo não têm sido exceção, bem como, por vezes, comentários que desqualificam trabalhos em função de opções teórico-metodológicas, o que obrigava os editores a recorrer a pelo menos mais um revisor para a arbitragem, resultando em dilatação ainda maior do tempo para o processo de julgamento. Por outro lado, a vigilância sobre o (auto)plágio ainda é tema entre os editores, embora, com a Elsevier, essa cautela tenha sido beneficiada pela adoção de um software para identificação da má conduta acadêmica que a alimenta.

Não podemos deixar de mencionar, entre as dificuldades, a decisão de publicação, nas páginas da RBCE, do "Prêmio de Literatura Científica" do CBCE. No último quinquênio da gestão, dois prêmios foram atribuídos. O primeiro deles consistiu em 60 comunicações orais do XVIII Congresso Brasileiro de Ciências do Esporte/V Congresso Internacional de Ciências do Esporte (Conbrace/Conice) premiadas para publicação na RBCE. ${ }^{9}$ Isso "embaralhou" o trabalho cotidiano na revista, especialmente porque

\begin{abstract}
Os artigos selecionados pelos GTTs, em sua grande maioria, não chegaram à RBCE nas normas e layouts regulares, de maneira que tivemos que refazer quase todo o trabalho de editoração, ou seja, entrar no sistema SOAC, baixar vários artigos, inserir autoria, excluir o template do Conbrace/Conice, escrever para todos os(as) autores(as), receber os textos refeitos, corrigir aquilo que eles não corrigiram etc. Recentemente conseguimos dar fim a esta empreitada, o que nos permite afirmar que este número estará disponível nas próximas semanas. Nas condições em que operamos, foi impossível preparar este número especial (que corresponde, na prática a 4 números da RBCE em adição aos regulares, ou seja, a dois anos de publicação em um) e ao mesmo tempo manter a regularidade da RBCE e dos Cadernos de Formação da RBCE (EDITORIAL, v. 36, n. 1, 2014, p. 10).
\end{abstract}

Ao mesmo tempo em que tudo isso acontecia, dois importantes desafios editoriais se apresentavam. O primeiro diz respeito à autonomia financeira, tema retomado em mais de um editorial (v. 35, n. 4 de 2013; v. 36, n. 1 de 2014; v. 38, n. 4 de 2016; v. 39, n. 1 de 2017). Antes mesmo dos recentes cortes de recursos públicos destinados à ciência e tecnologia no país, ${ }^{10}$ o financiamento sempre foi sinônimo de incerteza para os editores. Aliás, como demonstramos, essa é uma inquietação que atravessa todo o ciclo de vida da RBCE (ALMEIDA; BASSANI; VAZ, 2015). Entra ano, sai ano, a história se repete: é necessário submeter às agências de fomento, especialmente ao CNPq e à Capes, um projeto solicitando financiamento para a RBCE. Na maioria das vezes, quando contemplados, o valor recebido, ainda que muito importante, não supria as necessidades da editoração. O dinheiro obtido por meio de editais, apesar de vital, não permite custar os atuais quatro números anuais da revista. Nessas circunstâncias, sempre coube ao CBCE arcar com os valores restantes,

9 O segundo foi decorrente da atribuição de 11 prêmios às melhores comunicações orais dos Grupos de Trabalho Temático apresentadas no XIX Conbrace/VI Conice de Vitória, em 2015. Estão disponíveis no v. 39, n. 3, 2017.

10 Entre tantos exemplos, consultar a matéria da revista Pesquisa Fapesp, disponível em: http://revistapesquisa. fapesp.br/2017/06/19/financiamento-em-crise/ 
o que deve ser observado no contexto da complexa manutenção da saúde financeira de uma instituição científica no Brasil. Nas condições em que os recursos são parcos, como assegurar os padrões exigidos pelos indexadores? Como garantir, em longo prazo, que os avanços alcançados permaneçam? Como propor políticas mais ambiciosas sem a garantia, e mesmo sem os recursos necessários para implementá-las? Como estimular a criatividade com restrições financeiras? Em suma, como manter um periódico em funcionamento, com elevados "padrões de cientificidade", com pouco dinheiro? O financiamento "[...] sistemático das revistas científicas, tema em amplo debate nacional neste momento, ainda é um problema para o qual não temos solução" (EDITORIAL, v. 35, n. 4, 2013, p. 807).

O Brasil não adotou, pelo menos não ainda, os modelos europeus e norte-americanos de financiamento, regidos, em grande medida pela mercantilização da editoração científica. A necessidade de serviços como DOI, formatação e publicação dos artigos em diferentes formatos, incluindo XML, emprego de ferramenta antiplágio, mais agilidade na publicação dos artigos aprovados etc., são algumas das exigências que indexadores, como SciELO, Scopus e WoS, têm demandado aos periódicos. Parte desses serviços era anteriormente realizado pelos indexadores, a exemplo da editoração em XML e atribuição de DOI, ambos pelo SciELO, mas, progressivamente, foram sendo transferidos aos próprios periódicos, gerando novas demandas para o processo de editoração. Isso tem consequências também para o mercado editorial, uma vez que a incorporação desses serviços por parte de editoras passa a ser condição para atenderem às demandas de periódicos que, por sua vez, necessitam de maiores recursos financeiros para seguirem publicando.

Na RBCE, uma consequência (esperada) da parceria com a Elsevier foi o aumento do custo produtivo de cada edição. Foi o preço pago, por assim dizer, para um passo importante na direção da profissionalização do processo. Isso fez aumentar o rigor dos editores quanto à extensão máxima dos textos, que faz algum tempo é de 35.000 caracteres. Submissões acima desse limite (prática rotineira no cotidiano das revistas) passaram a ser imediatamente rejeitadas pois extrapolavam a quantidade de caracteres de produção textual determinada em contrato com a editora (EDITORIAL, v. 37, n. 2, 2015; EDITORIAL, v. 38, n. 4, 2016).

Uma solução encontrada pelos editores, com a anuência da Diretoria Nacional do CBCE, para dirimir os problemas de financiamento, foi aplicar uma estratégia cada vez mais comum aos periódicos científicos brasileiros e bastante consolidada no exterior: o pagamento para publicação. Embora essa prática impopular tenha efetivamente começado no último ano de nossa gestão, essa política científica foi anunciada no editorial do primeiro número de 2014:

Outra questão importante é que a publicação de artigos originais e/ou de revisão na RBCE, após a aprovação, só ocorrerá mediante a associação do(s) autor(es) no CBCE ou, então, por pagamento de taxa de publicação. Essa é uma decisão tomada em conjunto e após muito debate e reflexão com a atual Diretoria Nacional do Colégio Brasileiro de Ciências do Esporte (CBCE), sendo concebida como uma iniciativa que visa fortalecer a entidade. Artigos já submetidos estão evidentemente isentos destas novas condições. A taxa de publicação para não sócios do CBCE será utilizada para complementar os recursos públicos que a RBCE obtém de órgãos de fomento e do Colégio Brasileiro de Ciências do Esporte [...]. Esta complementação é essencial para 


\begin{abstract}
assegurar periodicidade, qualidade, impacto e agilidade do periódico, em particular para manter os diversos avanços experimentados pela RBCE nos últimos anos. Essa contribuição, além disso, possibilitará a implantação de outras medidas editoriais anunciadas nos últimos números, como a tradução para o Inglês de manuscritos não submetidos neste idioma, procedimento sem prejuízo da leitura em Português dos artigos originalmente submetidos em língua nacional, os quais representam a maioria das contribuições divulgadas pela RBCE [...]. Assim que o manuscrito for encaminhado para editoração, o autor responsável receberá instruções da secretaria do CBCE de como proceder para o pagamento. Quando o(s) autor(es) forem associados ao $\mathrm{CBCE}$, repetimos, estarão isentos de qualquer taxa. O CBCE fornecerá aos autores os documentos necessários para comprovar o pagamento das taxas perante suas instituições de origem, programas de pós-graduação ou órgãos de fomento à pesquisa. No momento oportuno, apresentaremos mais detalhes sobre a cobrança (EDITORIAL, v. 36, n. 1, 2014, p. 10-11).
\end{abstract}

Com o aumento de associações, mais verba estaria disponível ao CBCE e, consequentemente, maiores seriam as chances de tais recursos serem aplicados na revista (mas, também, em outros setores do Colégio). Esperávamos que, em vez da taxa de publicação, os autores preferissem a associação na entidade, o que garantiria não só seu fortalecimento, mas, para os autores, a possibilidade de submeter outros artigos sem precisar pagar a taxa a cada trabalho aceito para publicação. O pagamento colocou, por sua vez, novas tarefas à equipe editorial, pois tornou-se imperativo controlar, com a Secretaria Nacional do CBCE, quem efetivamente fizera o pagamento da taxa ou, então, da associação. Exercício que começou difícil pois, no momento da implementação, não tínhamos integração entre a plataforma da RBCE e o sistema operacional utilizado na Direção Nacional. O serviço era manual, conferindo autor por autor, artigo por artigo. No caso de estrangeiros, a situação ainda era mais árdua dada a dificuldade que possuíam, ao menos naquele momento, da transferência financeira para o CBCE.

O segundo desafio que nos acompanhava era a publicação em inglês (traduzidos ou submetidos nesse idioma). Essa necessidade resulta de "[...] impasses com as exigências para os impressos científicos, que se veem 'obrigados' a publicar, independente das especificidades do campo, em língua inglesa, com o propósito de alcançar indexação em bases internacionalmente reconhecidas" (EDITORIAL, v. 39, n. 1, 2017, p. 1). Já em outro momento, perguntávamos "o que se ganha e o que se perde" com o imperativo da publicação em inglês:

Quais os impactos políticos dessa decisão para uma área com as características da Educação Física? O que representaria essa decisão para quem está no âmbito da intervenção profissional? O que significaria para um campo acadêmico que tem a seu dispor poucas revistas classificados nos estratos superiores do Qualis-periódicos? Problemas como esses necessitam de uma reflexão ampla, pois produzem impactos de curto e de longo prazo, talvez nem todos positivos, em qualquer área acadêmica (VAZ; ALMEIDA; BASSANI, 2014, p. 754).

Sob a rubrica geral da internacionalização, os periódicos brasileiros têm sido pressionados por essa exigência. A internacionalização "[...] desponta como meta e mito, 
simultaneamente" (EDITORIAL, v. 36, n. 4, 2015). A intenção parece ser a de disseminar, em língua inglesa, o conhecimento produzido no país e, ao mesmo tempo, atrair a submissão de papers produzidos no exterior. ${ }^{11}$ No extremo, é fazer a ciência produzida no país em inglês, que é a atual linguagem universal, por assim dizer, da comunidade científica. Esse entendimento é muito visível nos "Critérios, política e procedimentos para a admissão e a permanência de periódicos científicos na Coleção SciELO Brasil" (2014). ${ }^{12}$ O assunto é do maior interesse, pois a Educação Física tem algumas revistas indexadas na SciELO e tantas outras que a têm como objeto de interesse. O documento apresenta as "[...] linhas prioritárias de ação do Programa SciELO/Fapesp em prol da profissionalização, internacionalização e do financiamento sustentável dos periódicos que indexa e publica" (SciELO, 2014, p. 4). Três dos quatro editoriais das edições de 2015 se reportam a essa problemática. No v. 37, n. 3 de 2015, destacamos três diretrizes do documento SciELO que merecem atenção. Elas se referem: às porcentagens mínimas anuais esperadas e recomendadas de artigos originais e de revisão no idioma inglês, que, para o caso das revistas da grande área da Saúde, como a RBCE, é de 80\% dos artigos publicados; às porcentagens mínimas esperadas e recomendadas de autores com afiliação institucional no exterior por área temática que, para as revistas da mesma grande área, é de 25\% o mínimo (35\% é o recomendado pela SciELO); à necessidade de maximizar a participação de editores (20\% mínima e 30\% recomendada) e revisores afiliados a instituições do exterior (25\% mínima e $30 \%$ recomendada). ${ }^{13}$ A expectativa da base era que seus periódicos pudessem implementar essas medidas a partir de 2016. Ao menos no caso da RBCE, não foi possível atender plenamente a todas essas exigências. As razões para isso precisam ser buscadas considerando as especificidades dos campos de origem a que as revistas se vinculam, em lugar de se atribuir a suposta insuficiência à inépcia dos editores que conduzem as políticas da revista. Os editores, por sua vez, lançam dúvidas sobre o conteúdo do documento:

Como as revistas indexadas vão se posicionar diante dessa nova normativa do SciELO, agora condição indispensável para nele adentrar e manter-se, é algo que saberemos nos próximos meses. É momento, todavia, de problematizar o que se ganha e o que se perde com esse regulamento, refletir a respeito de seus impactos nas políticas editoriais das revistas e, claro, num campo com as características da educação física (EDITORIAL v. 37, n. 3, 2015, p. 205).

A questão dos artigos em inglês oferece, no entanto, desafios mais complexos, já que suas consequências para a produção e disseminação de conhecimento não são

11 Essa meta/mito é resultado da baixa visibilidade da produção científica nacional, quando comparada com o quadro identificado em outros países. É o que mostra o recente levantamento realizado pela agência Thomson Reuters (http://www1.folha.uol.com.br/ciencia/2014/09/1515944-brasil-tem-so-4-dos-3215-cientistas-cujaspesquisas-tem-maior-impacto.shtml), em que o Brasil aparece com apenas quatro pesquisadores entre os 3.215 cientistas cujas pesquisas têm maior impacto no mundo. Essa avaliação foi feita com base em um levantamento de trabalhos acadêmicos publicados, de 2002 a 2012, nos periódicos científicos da base de dados "Web of Science", cuja proprietária é a própria Thomson Reuters. Entre os pesquisadores mais impactantes, não havia nenhum representante das ciências humanas e sociais.

12 Doravante "Critérios SciELO Brasil".

13 A versão atual dos Critérios SciELO Brasil (2017) mantém essas porcentagens. 
desprezíveis. Nesse contexto, uma vez mais é preciso pensar sobre o papel que um periódico deve ter na promoção das pesquisas em uma área de conhecimento. Trata-se de uma questão importante não apenas para a RBCE e outros periódicos nacionais, mas para toda a comunidade da educação física/ciências do esporte. Afinal, a RBCE não é mais do que uma expressão dessa área de conhecimento (EDITORIAL, v. 37 , n. 1, 2015, p. 1).

Internacionalizar obriga ao passo de redigir em inglês, seja originalmente ou em forma de tradução, o que requer recursos não apenas, mas principalmente, financeiros. Por outro lado, significa receber artigos de pesquisadores de outros países, assim como manter editores e revisores também extrafronteiras. Somam-se ainda as dificuldades técnicas de estruturação material dos periódicos. Que queremos fazer com tudo isso além de ganhar pontos no atletismo acadêmico? Como dar conta disso sem profissionalizar as editorias? $\mathrm{O}$ que, definitivamente, queremos com as humanidades em Educação Física/Ciências do Esporte? (EDITORIAL, v. 37, n. 4, 2015, p. 305-306).

Na ocasião da publicação do documento, fizemos contato por e-mail com a diretoria da SciELO solicitando a relativização de critérios. Afinal, a RBCE, apesar de ser uma revista que está na grande área da Saúde, também publica trabalhos de Humanidades. É, na prática, multidisciplinar. Não tivemos, todavia, sucesso com a demanda, pois, para aquela base, somos um periódico de Saúde, já que assim a área de Educação Física está classificada no CNPq e na Capes. As regras mudariam apenas se migrássemos de área, questão complexa e para a qual não há consenso no âmbito do CBCE e na própria área acadêmica Educação Física.

Considerando o quadro exposto, avaliamos que é preciso cautela diante dos atuais "Critérios SciELO Brasil". É isso o que propõe a carta que resulta do "Fórum de Editores Científicos da Fundação Oswaldo Cruz" (Fiocruz), bem como a "Carta de São Paulo" do "Fórum de Editores da Saúde Coletiva", manifestações que questionam os "Critérios SciELO Brasil". A carta da Fiocruz sugere um

[...] olhar mais cuidadoso para as especificidades e os percalços de cada área, reconhecendo-se que a internacionalização não é uma meta que deva ser seguida por todo periódico científico. Os novos critérios do SciELO devem ser flexíveis a ponto de permitir que o portal abrigue periódicos que não perseguem tal meta mas obedecem a padrões mínimos de profissionalismo (FIOCRUZ, 2014, p. 3-4).

Não se trata, portanto, de ser contra a internacionalização da produção, mas de incentivar esse processo sem provocar anomalias nos campos científicos e, também, sem deixar de problematizar seus impactos nas áreas que, como a Educação Física, se caracterizam pela intervenção profissional. Levando isso em conta, seguimos com práticas editoriais em favor da maior visibilidade internacional do periódico. Isso é notório especialmente graças ao incremento da colaboração de autores de língua espanhola (sobretudo da Argentina, Uruguai e Espanha), da publicação de alguns artigos em inglês, do convite a professores estrangeiros para compor os corpos de revisores e de editores. Além disso, 
seguimos com a prática de submeter o impresso a importantes indexadores. Obtivemos sucesso na Rede de Revistas Científicas de América Latina y el Caribe, España y Portugal (Redalyc), cuja indexação foi anunciada no editorial do v. 38, n. 1 de 2016, mas, também, fomos contemplados na Scopus, uma das mais imponentes bases de citações e resumos de literatura revisada por pares, cuja proprietária, talvez não por acaso, é a própria Elsevier. ${ }^{14}$

A presença nessas bases foi mais um fator a favorecer a visibilidade internacional da RBCE e consolidá-la como B1 no Qualis-Periódicos Capes (quadriênio 2013-2016) da área de Educação Física. ${ }^{15} \mathrm{~A}$ promoção da RBCE, periódico com alta e inequívoca aderência a uma ou mais subáreas da Área 21, para os estratos superiores do Qualis, depende da obtenção do Fator de Impacto, métrica que reflete o número médio de citações de artigos científicos publicados por determinado periódico (Capes, 2017). Esse indicador é disponibilizado pelo Journal of Citation Reports, publicado pelo Institute for Scientific Information (ISI) e editado pela empresa Thomson Reuters Scientific, que é proprietária da base Web of Science. Chegamos a anunciar, em quatro editoriais da RBCE (v. 35, n. 2 de 2013; v. 35, n. 3 de 2013; v. 35, n. 4 de 2013; v. 38, n. 1 de 2016), nossa indexação no Web of Science, mas retificamos essa informação no último editorial de 2016, baseados no fato de a notícia ter sido dada

[...] com base na divulgação, no site da Thomson Reuters, empresa responsável pela base WoS, de que a RBCE e outras duas revistas da área de Educação Física haviam sido incluídas nessa base. Apesar de a informação estar correta, a incorporação da RBCE a WoS aconteceu em função da disponibilização junto àquela base, também em 2013, do SciELO Citation Index, do qual esse periódico efetivamente faz parte. No entanto, o SciELO Citation Index não integra a chamada Core Collection da Web of Science, que inclui, entre outras, as bases Science Citation Index Expanded (SCIE) e Social Sciences Citation Index (SSCl), duas das bases vinculadas ao Journal Citation Reports (JCR), no qual são divulgados o fator de impacto (FI) e outras métricas relacionadas. Nesse sentido, e diferentemente do que havíamos informado na plataforma da revista em 27 de fevereiro de 2015, a RBCE não receberá FI a partir de 2016. Ainda sobre esse assunto, informamos que temos trabalhado para submeter a RBCE à indexação em uma das duas bases acima mencionadas, integrantes da Core Collection da Web of Science, o que permitirá à revista, no futuro, receber FI (EDITORIAL, v. 38, n. 4, 2016, p. 314).

Tomamos a decisão de encerrar nosso ciclo na RBCE antes de essa meta ser concretizada, pois os estudos realizados em parceria com a Elsevier indicavam que possivelmente o fator de impacto que seria atribuído à revista em um eventual pedido de indexação ao Web of Science seria suficiente apenas para classificá-la no último estrato da Science Citation Index $(\mathrm{SCl})$, resultando na não recomendação de indexação e produzindo uma quarentena de cinco anos para uma nova submissão. Esse mesmo editorial anunciava o

14 O anúncio dessa indexação foi feito no editorial do v. 35, n. 3 de 2013; antes, portanto, de a RBCE assinar contrato com a Elsevier.

15 Destaque-se que, na área de Educação, o periódico alcançou a classificação A2. 
início da despedida da equipe editorial em frente à RBCE, o que se concretizou com a preparação dos quatro números de 2017, com o processo de transição para a nova editoria, no segundo semestre de 2017, e com a assinatura do editorial de despedida na primeira edição de 2018 (EDITORIAL, v. 40, n. 1, 2018).

Antes disso, porém, ainda tivemos tempo para pontuar outro tema e é com ele que finalizamos este relato dos últimos anos de nossa gestão editorial. Trata-se da reflexão sobre o "foco e o escopo" da RBCE, o que passa pela problematização "do que publicar" ou da "decisão sobre nós mesmos", para citar os títulos editoriais que se reportaram a isso. Reconhecemos o significativo crescimento da produção do conhecimento em Educação Física e Ciências do Esporte, mas questionamos se esse volume corresponde à inovação na pesquisa ou, ao contrário, significa a "[...] prevalência de muito material reiterativo, ainda que corretamente feito. Em outras palavras, muitos na área dominam formas de fazer pesquisa e apresentar seus resultados, mas nem sempre esses apresentam, de fato, novas abordagens e questões" (EDITORIAL, v. 38, n. 3, 2016). Isso explicaria, segundo a avaliação de Lovisolo (2014), a abundância de dois tipos de artigo: a) mais sobre o mesmo; b) muito sobre coisa nenhuma. A relevância e o ineditismo das pesquisas não se configuram, efetivamente, como critérios definidores de aprovação ou exclusão da avaliação (VAZ; ALMEIDA; BASSANI, 2014). Importam menos suas contribuições substantivas que o nível das revistas onde publicou seus artigos (LOVISOLO, 2014). Diante de tal cenário, anunciamos (EDITORIAL, v. 38, n. 3, 2016) que a RBCE vinha tentado fazer uma avaliação prévia que incluía foco e escopo, mas que também considerasse o interesse da Educação Física/Ciências do Esporte e respeitasse a identidade que esse periódico tem construído.

Outra questão premente, continuavam os editores em sua análise sobre o foco e o escopo, refere-se à posição da Educação Física/Ciências do Esporte na grande área da Saúde, em especial a presença, em seu interior, de trabalhos oriundos das Ciências Humanas e Sociais. Afinal, programas de pós-graduação

[...] apresentam pesquisadores de humanidades, ainda que em número muito menor do que aqueles vincados na saúde; bolsas de produtividade em pesquisa e outras modalidades de financiamento são destinadas a pesquisadores de história da Educação Física e dos esportes, de formação de professores e outras subáreas correlatas; os periódicos apresentam um equilíbrio variável entre artigos de uma e outra área. A RBCE tem mantido há vários anos uma relação numérica igualitária entre trabaIhos de saúde e humanidades, fiel ao projeto do Colégio Brasileiro de Ciências do Esporte de representar a pluralidade da área. ${ }^{16} \mathrm{O}$ próprio $\mathrm{CBCE}$, no entanto, apresenta dificuldades nessa representação, o que se pode observar em seus grupos de trabalho temático, quase todos dedicados ao estudo e debate de questões internas às humanidades. Já sabemos que a delimitação de objetos, metodologias e abordagens, bem como os critérios de avaliação, não são sempre os mesmos em diferentes áreas ou subáreas de conhecimento (EDITORIAL, v. 37, n. 4, 2015, p. 305)

16 Apesar disso, os pesquisadores da área sociocultural ou pedagógica são vistos como "segunda classe" ou de "segunda categoria", pois suas funções e status se configuram diferentemente dos padrões dominantes. Isso tem provocado denegação de reconhecimento do conhecimento produzido no âmbito das "humanidades" em Educação Física. 
Essa pluralidade coloca desafios à definição de foco e escopo mais bem delimitados, o que nos leva a perguntar: dada a amplitude da área, “[...] o que pode ser um artigo em educação física? Aquele que é ou poderia ser produzido em um programa de pós-graduação em educação física? Aquele concebido no interior de um interesse pela intervenção pedagógica em que as práticas corporais sejam dominantes, dentro ou fora da escola?" (EDITORIAL, v. 38, n. 2, 2016, p. 105). Sem procurar uma norma que balizasse em definitivo essas questões e "Sem desconsiderar a pesquisa básica, é bom lembrar que Educação Física é uma área de intervenção pedagógica - e as Ciências do Esporte devem estar a serviço dela" (EDITORIAL, v. 39, n. 4, 2017, p. 329). Concluímos a reflexão advogando que, talvez, fosse preciso que as pesquisas encontrassem com mais frequência a prática pedagógica, na escola e fora dela, de modo que um polo alimentasse o outro e que, no extremo, "[...] quase que cada um não seja mais um polo da equação, mas que se determinem mutualmente" (EDITORIAL, v. 39, n. 4, p. 329). Essa defesa, ao menos se considerarmos o diagnóstico de Bracht (2015), é urgente como nunca. É um convite, portanto, à reflexão sobre a reificação da prática científica em nossa área, numa tentativa de retomar a sua tradição, vale dizer, sua especificidade como prática social marcada pela intervenção pedagógica, compreensão então esquecida pelo surto cientificista que tanto impacto tem na área e, portanto, nas atividades dos editores de revista em Educação Física.

\title{
CONSIDERAÇÕES FINAIS OU “COMO NÃO SER EXCESSIVAMENTE GOVERNADO”...
}

\begin{abstract}
Até agora, todos esses favorecedores do homem que se chamam filósofos — os quais por si mesmos raramente tiveram o sentimento de serem os amigos da sabedoria, mas antes loucos e pontos de interrogação perigosos - acharam seu trabalho duro, indesejado, ingrato e impreterível, mas do qual reconheceram a grandeza ao representar a má consciência do tempo em que viveram (NIETZSCHE, 2001, p. 134).
\end{abstract}

Neste artigo realizamos um balanço dos últimos cinco anos de nossa gestão editorial na RBCE. Completamos, assim, o exercício realizado em outro texto (ALMEIDA; BASSANI; VAZ, 2015), dedicado a descrever as práticas científicas da RBCE registradas nos editoriais (de 1979 a 2013) de seu longo tempo de vida, ao mesmo tempo em que refletimos, outra vez (VAZ; ALMEIDA; BASSANI, 2015), sobre dificuldades, desafios e dilemas da editoração científica. ${ }^{17}$ Encerramos sem oferecer uma síntese do que foi analisado, mas com um comentário sobre o que poderia balizar o ofício de editor das revistas na sociedade contemporânea. É ocasião para relativizar os indicadores bibliométricos, as metas da ciência estabelecida e recorrer um pouco à Filosofia.

Valeria, para os editores de revistas científicas, algo que Michel Foucault (1999) escreveu a respeito da "atitude crítica", a capacidade de não ser excessivamente governado, a arte da indocilidade raciocinada, da desobediência voluntária. Não querer ser governado

17 Essas dificuldades, desafios e dilemas nos impulsionaram a organizar, em 2014, um dossiê temático dedicado à sua reflexão (RBCE, 2014). 
implica não aceitar como verdade o que uma autoridade (CNPq, Capes, Área 21, bases indexadoras etc.) sustenta ser verdadeiro, a menos que haja boas razões para aceitá-lo, em pleno exercício de autonomia. Nesse horizonte, ficaria a expectativa de que os atuais critérios de avaliação da produção científica e dos periódicos, bem como o anseio pela internacionalização, antes comentados, poderiam ser vistos a partir de novos ângulos, caso esse dessubjugamento fosse praticado em relação às políticas da verdade em curso. Lamentavelmente não é isso que vemos, com honrosas exceções, ${ }^{18}$ nos fóruns da área dedicados ao tema, já que vozes dissonantes ao discurso oficial são recebidas com ceticismo, pois a "filosofia" do sistema, aquilo que a orienta centralmente, não pode ser questionada a ponto de repensá-lo conforme as demandas e propostas internas das (sub)áreas.

É por isso que o

[...] momento exige um esforço de iluminação de pressupostos que são colocados em ação e que sustentam a crença na ciência para evitar que no campo da Educação Física ela seja elevada à condição de uma tecnocracia total [...]. Esse esquecimento ameaça cobrir com um manto o campo acadêmico da EF, abafando e asfixiando formas alternativas de pensar (BRACHT, 2015, p. 3).

Os editores não deveriam perder de vista a dimensão política de seu ofício. Deveriam perguntar se "[...] a atividade editorial no campo da Educação Física contribui para o aumento da liberdade acadêmica, a formação profissional e cívica (ética)?" (LOVISOLO, 2014 , p. 710). Não devem ser, segue o autor (2014), meros administradores do fluxo de pareceres. Devem tomar distância do que fazem, perguntar-se o que é certo fazer e "[...] desenvolver uma leveza para julgar os critérios aos quais nos amarramos enquanto verdades sem possibilidades de questionamento. Temos que abrir para novos critérios de avaliação da produção" (LOVISOLO, 2014, p. 713).

Ao assumir o indesejável e aborrecido exercício de ser arcanos da "má consciência de sua época", os editores poderiam ser "contemporâneos" às exigências que o seu próprio tempo impõe, ao menos conforme o sentido que Agamben (2009) confere ao conceito. Para esse filósofo, contemporâneo é aquele que não coincide exatamente com o seu tempo, nem está totalmente adequado às suas pretensões, sendo, nesse sentido, inatual. Só assim consegue colocar o próprio tempo e a experiência que nele se realiza em questão. Quando tomamos essa perspectiva, podemos nos perguntar se os editores científicos não coincidem muito plenamente com a atualidade, aderindo a ela em todos os seus aspectos, ou não.

Os editores, assim defendemos, deveriam ser extemporâneos, na medida em que ousassem apontar controvérsias de algo de que nossa atualidade se orgulha: o sistema de avaliação de pós-graduação, suas metas de produtividade e visibilidade (internacionalização) aplicadas à divulgação científica. Dizer que os editores devem ser intempestivos não significa que eles devem defender um retorno a um passado nostálgico ou viver em outro tempo que não este. Um editor é contemporâneo na medida em que pertence a este tempo, 
julho/2018

mas dele se distancia. É exatamente esse anacronismo e esse deslocamento que permitem ao contemporâneo ser capaz de apreender sua época. Nesse contexto, os editores não podem prescindir de, nas "luzes" do tempo, identificar sua escuridão. Isso pressupõe sair da inatividade e assumir uma "atitude crítica" com o propósito de

[...] neutralizar as luzes que provêm da época para descobrir as suas trevas, o seu escuro especial, que não é, no entanto, separado daquelas luzes. Pode dizer-se contemporâneo apenas quem não se deixa cegar pelas luzes do século e consegue entrever nessas a parte da sombra, a sua íntima obscuridade (AGAMBEN, 2009, p. 63-64).

Qual é a escuridão de nossa época? Essa escuridão corresponde à reificação da prática científica na Educação Física (sua academicização e disciplinarização), que cega a área pelas luzes da ciência e dificulta formas alternativas de pensar o ofício de editores no campo. Na medida em que reconheçamos e assumamos isso, estaremos, quem sabe, no caminho de transformar nossa relação com o que é "atual" na atividade científica da área, aí incluído o ofício que por tanto tempo exercemos na RBCE.

Desejamos aos nossos sucessores uma boa jornada, na discreta expectativa que essas reflexões possam de alguma forma inspirá-los.

Vida longa à RBCE!

\section{REFERÊNCIAS}

ABRASCO. Carta de São Paulo. Carta do "Fórum de Editores da Saúde Coletiva" realizado em 18 de novembro de 2014, em São Paulo.

AGAMBEN, G. O que é o contemporâneo. Chapecó: Argos, 2009.

ALMEIDA, F. Q.; BASSANI, J. J.; VAZ, A. F. Vicissitudes de uma história da RBCE: 35 anos de editoração científica (1979-2013). Motrivivência, Florianópolis, v. 27, n. 46, p. 135-153, 2015.

BETTI, M. Sobre teoria e prática: manifesto pela redescoberta da educação física. EFdeportes, Buenos Aires, ano 10, n. 91, 2005. Disponível em: www.efdeportes.com/efd91/ef.htm. Acesso em: 11 ago. 2011.

BRACHT, V. Educação física, método científico e reificação. In: STIGGER, M. P. Educação Física + Humanas. São Paulo: Autores Associados, 2015. p. 1-21.

COORDENAÇÃO de aperfeiçoamento de pessoal de nível superior (Capes). Critérios de classificação Qualis Área 21: Educação Física, Fisioterapia, Fonoaudiologia e Terapia Ocupacional. Disponível em: https://www.capes.gov.br/images/documentos/ Qualis_periodicos_2016/CRIT\%C3\%89RIOS_DE_CLASSIFICA \%C3\%87\%C3\%83O QUALIS_EDUCA $\%$ C3\%87\%C3\%83O_F\%C3\%8DSICA.pdf. Acesso em: 15 de abr. de 2018. 
DEVÍS-DEVÍS, J.; VILLAMÓN, M.; VALCÁRCEL, J. V. Revistas iberoamericanas de Educación Física/Ciencias del Deporte presentes en Web of Science: evaluación y desafíos Revista Brasileira de Ciências do Esporte, Florianópolis, v. 36, n. 4, p. 723-732, 2014.

FIOCRUZ. A internacionalização dos periódicos científicos brasileiros. Carta do Fórum de Editores Científicos da Fundação Oswaldo Cruz (Fiocruz) realizado em outubro de 2014, em São Paulo.

FOUCAULT, M. O que é a crítica. Roma: Donzelli Editore, 1999.

HABERMAS, J. Pensamento pós-metafísico. Rio de Janeiro: Tempo Brasileiro, 2002.

. Consciência moral e agir comunicativo. Rio de Janeiro: Tempo Brasileiro, 2003.

LOVISOLO, H. R. Gestão de revistas: algumas considerações e sugestões para o debate. Revista Brasileira de Ciências do Esporte, Florianópolis, v. 36, n. 4, p. 708-714, 2014. MANOEL, E. J.; CARVALHO, Y. M. Pós-graduação na educação física brasileira: a atração (fatal) para a biodinâmica. Educação e Pesquisa, São Paulo, v. 37, p. 389-406, 2011.

NIETZSCHE, F. Além do bem e do mal ou um prelúdio de uma filosofia do futuro. Curitiba: Hemus livraria, 2001.

REVISTA BRASILEIRA DE CIÊNCIAS DO ESPORTE. Rio de Janeiro: Elsevier, v. 36, n. 4, p. 707-808, 2014. Quadrimestral.

SCIELO. Critérios, política e procedimentos para a admissão e a permanência de periódicos científicos na Coleção SciELO Brasil, São Paulo, 2014.

VAZ, A. F.; ALMEIDA, F. Q; BASSANI, J. J. Revista Brasileira de Ciências do Esporte: dificuldades, desafios e dilemas da editoração científica. Revista Brasileira de Ciências do Esporte, Florianópolis, v. 36, n. 4, p. 752-758, 2014.

\section{FONTES}

EDITORIAL. Revista Brasileira de Ciências do Esporte, Florianópolis, v. 32 , n. 2-4, dez. 2010.

EDITORIAL. Revista Brasileira de Ciências do Esporte, Florianópolis, v. 35 n. 2, p. 261262, abr./jun. 2013.

EDITORIAL. Revista Brasileira de Ciências do Esporte, Florianópolis, v. 35 n. 3, p. 545546, jul./set. 2013.

EDITORIAL. Revista Brasileira de Ciências do Esporte, Florianópolis, v. 35 n. 4, p. 807808, out./dez. 2013.

EDITORIAL. Revista Brasileira de Ciências do Esporte, Florianópolis, v. 36, n. 1, p. 9-12, jan./mar. 2014.

EDITORIAL. Revista Brasileira de Ciências do Esporte, Florianópolis, v. 36, n. 4, p. 607, out./dez. 2014.

EDITORIAL. Revista Brasileira de Ciências do Esporte, Florianópolis, v. 37 , n. 1, p. 1, jan./mar. 2015.

EDITORIAL. Revista Brasileira de Ciências do Esporte, Florianópolis, v. 37, n. 2, p. 107, abr./jun. 2015. 
julho/2018

EDITORIAL. Revista Brasileira de Ciências do Esporte, Florianópolis, v. 37, n. 3, p. 205206, jul./set. 2015.

EDITORIAL. Revista Brasileira de Ciências do Esporte, Florianópolis, v. 37, n. 4, p. 305306, out./dez. 2015.

EDITORIAL. Revista Brasileira de Ciências do Esporte, Florianópolis, v. 38, n. 1, p. 1-2, jan./mar. 2016.

EDITORIAL. Revista Brasileira de Ciências do Esporte, Florianópolis, v. 38, n. 2, p. 105106, abr./jun. 2016.

EDITORIAL. Revista Brasileira de Ciências do Esporte, Florianópolis, v. 38, n. 3, p. 211 212, jul./set. 2016.

EDITORIAL. Revista Brasileira de Ciências do Esporte, Florianópolis, v. 38, n. 5, p. 313314, out./dez. 2016.

EDITORIAL. Revista Brasileira de Ciências do Esporte, Florianópolis, v. 39, n. 1, p. 1, jan./mar. 2017.

EDITORIAL. Revista Brasileira de Ciências do Esporte, Florianópolis, v. 39, n. 3, p. $217-$ 218, jul./set. 2017.

EDITORIAL. Revista Brasileira de Ciências do Esporte, Florianópolis, v. 39, n. 4, p. 329, out./dez. 2017.

EDITORIAL. Revista Brasileira de Ciências do Esporte, Florianópolis, v. 40, n. 1, p. 1-2, jan./mar. 2018.

Autores convidados pela comissão editorial da Motrivivência para participar da Seção Temática dessa edição (21/fev/2018) 